\title{
Xerostomia and hyposalivation in orthogeriatric patients with fall history and impact on oral health-related quality of life
}

\section{Anna Greta Barbel \\ Pia Schmidt ${ }^{\prime}$ \\ Michael Bussmann ${ }^{2}$ \\ Henning Kunter ${ }^{2}$ \\ Michael Johannes Noack' \\ Gabriele Röhrig ${ }^{3}$ \\ 'Department of Operative Dentistry and Periodontology, Center of Dental Medicine, University of Cologne, Köln, Germany; ${ }^{2}$ Department of Orthogeriatrics, Evangelisches Krankenhaus Köln Kalk, Cologne, Germany; ${ }^{3}$ Geriatric Diagnostic Center, MVZ Medicum Köln Ost, Cologne, Germany}

\section{Video abstract}

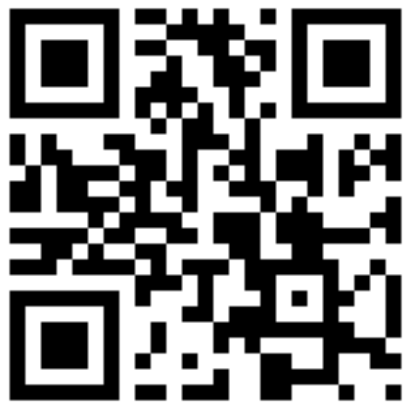

Point your SmartPhone at the code above. If you have a QR code reader the video abstract will appear. Or use:

http://youtu.be/hlwhhx6yD40

Correspondence: Anna Greta Barbe Department of Operative Dentistry and Periodontology, Centre of Dental Medicine, University of Cologne, Kerpener Str. 32, Köln 5093I, Germany Tel +49 22I 47898568 Email anna.barbe@uk-koeln.de
This article was published in the following Dove Press journal: Clinical Interventions in Aging

Purpose: Falls are a common cause of morbidity and mortality in older people, and identification of risk indicators and risk factors to prevent falling is essential. Dry mouth (xerostomia and hyposalivation) can exacerbate conditions known to be fall risk indicators, such as nutritional status and sarcopenia. But there is little evidence regarding whether it is an independent risk factor for falling. We explored xerostomia prevalence and intensity and objective salivation rates in hospitalized geriatric patients to determine whether they were associated with an increased risk of falling.

Patients and methods: Hospitalized geriatric patients with and without a fall history were compared. We investigated several oral health issues including xerostomia, stimulated and unstimulated salivation rates, total number of teeth and prosthetics, periodontal status, and oral health-related quality of life.

Results: Forty patients were included, 28 in the fall history group and 12 in the control group. All patients had oral health issues that impacted on their oral health-related quality of life. However, there were no significant differences between the groups, including xerostomia and hyposalivation, apart from increased dysphagia and less flavor in food in patients with a fall history.

Conclusion: Dry mouth does not appear to be an independent risk factor for falling in this population, but oral health was impaired. Thus, it is important that dentists and geriatricians are aware of and investigate these conditions in their patients and that appropriate action is taken to reduce the consequences of impaired oral health, including a potential reduction in falls.

Keywords: dry mouth, falls, gerodontology, Oral Health Impact Profile, geriatric syndrome

\section{Introduction}

The prevalence of falls increases with age, affecting $28 \%-35 \%$ of older people globally every year. ${ }^{1}$ Falls are the most common cause of trauma and trauma-related deaths among older people, ${ }^{2}$ and morbidity and mortality after a fall are correlated with frailty, ${ }^{3}$ while age constitutes the strongest predictor of mortality. ${ }^{4}$ In $40 \%-60 \%$ of cases, falls are associated with major lacerations, fractures, or traumatic brain injuries, ${ }^{5}$ resulting in reduced physical activity, deconditioning, functional decline, impaired ability to perform daily activities, social isolation, reduced quality of life, depression, increased risk of subsequent falls, and institutionalization. ${ }^{6-9}$ Nearly $95 \%$ of all hip fractures are caused by falls, $95 \%$ of patients with hip fractures are discharged to nursing homes, and $20 \%$ of patients with a hip fracture die within a year. ${ }^{10}$

Therefore, it is important to identify risk indicators and factors to better prevent falls among older people. In the community, these include previous falls, demographic 
characteristics, health habits, pain, chronic diseases, medication use, disabilities, and sarcopenia. ${ }^{11-13}$ In light of the shift toward interdisciplinary scientific approaches to patient management, certain risk factors are of importance not only for geriatricians and gerontologists but also for dentists. In particular, polypharmacy (often defined as the use of four or more drugs) is commonly described as a risk factor in patients who fall. ${ }^{14}$ Furthermore, the use of specific drugs (eg, antidepressants, sedatives and hypnotics, neuroleptics and antipsychotics, antihypertensives, and anticonvulsants) have been linked to an increased risk of falls. ${ }^{15-17}$ Yet although most of these prescription medicines have dry mouth as a side effect and impact on oral health, ${ }^{18}$ it is surprising that dry mouth and other oral health issues are not yet regularly listed in the long list of risk factors for falls. As both nutritional status and sarcopenia are risk factors for falls among geriatric patients ${ }^{19,20}$ - and dry mouth is associated with dysphagia, taste disturbances, and often reduced and changed nutritional intake and therefore sarcopenia ${ }^{21,22}$ - we assume that subjective and objective dry mouth might also serve as independent risk factors or at least risk indicators. Xerostomia (abnormal subjective dryness of the mouth due to insufficient secretions) - in contrast to hyposalivation (the objective finding of decreased salivary production, defined as a whole stimulated salivary rate of $\left.<0.5-0.7 \mathrm{~mL} / \mathrm{min}^{23,24}\right)^{25}$ - defines the dry mouth experienced after use of medications. ${ }^{26}$ There is evidence to suggest that a $50 \%$ decrease in salivary flow will result in xerostomia; however, xerostomia may also occur in patients with normal salivary flow rates. ${ }^{27}$ Salivary gland hypofunction disrupts the normal homeostasis of the oral cavity, causing a range of oral diseases including dental caries, candidiasis, taste disturbances, and difficulties with chewing, swallowing, and speaking. ${ }^{28}$

The correct definition of dry mouth as a risk factor for falls is challenging, as it is difficult to discriminate between the high number of causes of dry mouth problems factors such as Sjögrens's syndrome, age, gender, and head and neck radiotherapy. ${ }^{29,30}$ Also it is difficult to discriminate between possible side effects of medications and the underlying diseases for which these medications have been described and their influence on dry mouth conditions. In addition, dry mouth independently shows high prevalence among the elderly. ${ }^{31}$ Furthermore, our own recent findings have shown that older (Parkinson's disease) patients tend to underestimate their dry mouth conditions and rarely report them to their dentists. ${ }^{32}$

In the literature, only limited data regarding the association between xerostomia, hyposalivation, and fall prevalence in orthogeriatric patients with fall history, as well as how these patients perceive their xerostomia, are available. Orthogeriatric patients are elderly patients (here inpatients) in need of an interdisciplinary orthopedic and geriatric approach based on a concept of orthogeriatric co-management. ${ }^{33}$ Additionally, it is not clear whether orthogeriatric patients with fall history suffer from impaired oral health-related quality of life (OHrQoL) and the impact of their dry mouth conditions. Therefore, we conducted an interdisciplinary clinical comparison between a group of well-characterized hospitalized orthogeriatric patients with a fall history and a group of hospitalized geriatric patients without a fall history. Our aim was to explore xerostomia prevalence and intensity as well as objective salivation rates in the two groups. In addition, the OHrQoL was investigated, as was the association between subjective and objective dry mouth and fall prevalence. We hypothesized that patients with fall history suffer more often from xerostomia and hyposalivation compared with non-fallers, as well as impaired OHrQoL influenced by their dry mouth conditions.

\section{Patients and methods}

\section{Participants}

Geriatric patients either admitted from the community to the orthogeriatric department with a fall and trauma history or admitted to the geriatric care unit without a fall history (controls) were included in the study. All participants were recruited from the urban hospital Evangelisches Krankenhaus Kalk, Germany, either from the department of traumatology, orthopedics, and orthogeriatrics (ATZ) or the department of geriatric medicine. Patients were included if they were older than 70 years, were able to give written informed consent, and were hospitalized at the ATZ. All eligible participants who were willing to participate were included in the study from December 2017 until April 2018. None of the participants suffered from Sjögren's syndrome, had or have ever had head and neck malignancies, nor radiation therapy in the head and neck region.

\section{Parameters assessed}

\section{Clinical characteristic/medical history}

Age, comorbidities, dependency level, nutritional status via the Mini Nutritional Assessment, ${ }^{34}$ and prescribed medications were documented, based on the medical records of the ATZ. Based on the recommendations of the European Working Group on Sarcopenia in Older people, hand grip strength measured by a dynamometer (DHD-1 Digital Hand Dynamometer, Saehan Company, South Korea) was used as marker for sarcopenia. ${ }^{35}$ 


\section{Questionnaires}

All questionnaires were completed in a quiet room without help or interference where possible. If participants asked for help with reading or writing, one dental nurse (PS) was present to assist. Participants could take as much time as they needed. The questionnaires were finalized and collected before the clinical examinations. The questionnaires included the OHrQoL via the German version of the Oral Health Impact Profile (OHIPG-14) ${ }^{36}$ and the Xerostomia Questionnaire (XQ). ${ }^{37}$

\section{Xerostomia}

Self-assessed xerostomia was classified by answering "yes" or "no." Additionally, a visual analog scale (VAS) score $(0-10 \mathrm{~cm})$ was obtained from the participants, where they rated their subjective burden from 0 (completely normal saliva) to 10 (no saliva at all).

\section{German version of the OHIPG-I4}

Oral health was measured with the OHIPG-14 questionnaire. ${ }^{36}$ The questions of the OHIPG-14 monitor pain, physical, psychological, and social limitations, and disabilities on a 5 -level scale ranging from never (score 0), hardly ever (1), occasionally (2), fairly often (3) to always (4). The results are expressed as the sum of the scores for the 14 questions (maximum 56).

\section{$\mathrm{XQ}$}

The XQ consists of three parts. Patients were asked to estimate the degree (grade 0-3) of oral dryness, pain, taste loss, and dysphagia. In addition, patients answered 15 questions regarding the perceived impact of xerostomia on their quality of life. For each question, participants encircled a number from 1 to 5, reflecting the measure of agreement with the statement. ${ }^{37}$

\section{Oral health characteristics}

The total number of teeth and the prosthetic situation were described and the periodontal status was documented by the community periodontal index of treatment needs. ${ }^{38}$ The root caries index ( $\mathrm{RCI}$ ) was graded on a scale from $\mathrm{RC} 1$ (hard surface) to RC5 (soft surface), ${ }^{39}$ and oral hygiene was documented by the oral hygiene index $(\mathrm{OHI}){ }^{40}$

\section{Unstimulated salivation rates}

All saliva collections took place between 9 and 11 am in a quiet room of the orthogeriatric ward and were performed by the same examiner (PS). Participants were asked to relax for a couple of minutes before saliva collection. They were sitting in an ordinary chair bent forward and were asked to hold their mouth open and remain still, letting the saliva drip into a disposable cup held to the lower lips for 5 minutes. Volumes $(\mathrm{mL})$ were determined using luer slip syringes (BD Discardit II; Becton, Dickinson and Company, Franklin Lakes, NJ, USA). Saliva produced at a rate $<0.2 \mathrm{~mL} / \mathrm{min}$ was defined as objective hyposalivation.

\section{Stimulated salivation rates}

The participants did not consume any food or drinks 1 hour prior to the examination and did not brush their teeth during this time. Stimulated salivation rates were measured 1 hour minimum after the unstimulated salivation rates took place. The clinical collection of chewing-stimulated whole saliva samples has been outlined in detail elsewhere. ${ }^{41,42}$ In brief, stimulated saliva sampling was started by flushing in tap water followed by chewing on paraffin wax (Ivodent Vivadent AG, Liechtenstein, Ellwangen, Deutschland) (1 g) for 30 seconds. Subsequently, participants were instructed to spit continuously for 5 minutes in a sterile plastic cup to obtain the rate $(\mathrm{mL} / \mathrm{min})$, and during the last few seconds of the 5 minutes, the resting amount of saliva also was collected. Volumes $(\mathrm{mL})$ were determined using luer slip syringes (BD Discardit II; Becton, Dickinson and Company). Saliva produced at a rate $<0.7 \mathrm{~mL} / \mathrm{min}$ was defined as objective hyposalivation. ${ }^{43}$

\section{Sample size calculation}

No classic sample size calculation was performed. Because of the pilot nature of the study, we defined a realistic timespan for recruiting; therefore, all participants willing to participate were consecutively included between December 2017 and April 2018. A post-study sample size calculation for future studies with the results of the unstimulated salivation rates was performed.

\section{Ethics}

The University of Cologne local ethics review board (study number: 17-389, date of issue: 11/27/2017) granted approval for the study. The study was registered at the Deutsches Register für Klinische Studien (German Registry of Clinical Trials) with the study number DRKS00013230.

\section{Statistical analysis}

Continuous variables are summarized as mean (SD) values, contingent on distributional characteristics. Qualitative variables are described by count and percentage. The correlation of clinical measures with VAS values, OHIPG-14 total scores, and objective saliva amounts was calculated 
according to Spearman; only coefficients $\geq 0.3$ are reported. Distributions of paired and unpaired data were compared by rank-based methods, that is, Wilcoxon signed-rank test and Mann-Whitney $U$-test, respectively. ORs were calculated for stimulated and unstimulated salivation rates among study participants with and without fall history. All calculations were done with SPSS Statistics 24 (IBM Corporation, Armonk, NY, USA). Data were entered twice and reconciled in case of inconsistencies. $P$-values $<0.05$ were considered to indicate statistical significance (comparison-wise type I error control).

\section{Results}

\section{Clinical characteristics}

Twenty-eight geriatric trauma patients with a fall history and 12 controls without a fall history provided written informed consent and completed the study. Of the patients with fall history, 73\% were female and the mean age was 83 (SD: 7) years. All participants had regular medical and dental health insurance. There were no significant differences between patients with a fall history and controls regarding the number of remaining teeth $(P=0.082)$, the RCI $(P=0.391)$, and $\mathrm{OHI}$
$(P=0.140)$ (Table 1). Overall, 64\% of participants suffered from periodontitis, with no significant differences between the two groups.

\section{Xerostomia}

The mean xerostomia VAS score of orthogeriatric patients with fall history was 5.4 (SD: 2.7) vs 4.9 (SD: 2.4) among controls $(P=0.563)$. The values reported on the VAS did not correlate with increasing age, gender, RCI, or OHI, but did show a correlation with subjective dysphagia ( $r=0.451$, $P=0.016$ ). Regarding ORs, the combination between "no xerostomia" and "non-faller" was missing; therefore, no OR could be calculated.

\section{Salivation rates}

Sixty-four percent of patients with fall history suffered from objective hyposalivation regarding the unstimulated salivation rates and $75 \%$ regarding the stimulated salivation rates, $93 \%$ reported to suffer from xerostomia. There was no difference between stimulated $(P=0.883)$ or unstimulated $(P=0.492)$ salivation rates between patients with a fall history and controls, with a mean stimulated salivation rate of $0.4 \mathrm{~mL} / \mathrm{min}$

Table I Clinical characteristics

\begin{tabular}{|c|c|c|c|c|}
\hline & $\begin{array}{l}\text { Study participants, } \\
\text { n }\left(\%^{\mathrm{a}}\right)\end{array}$ & $\begin{array}{l}\text { Fall history group, } \\
\text { n (\%) }\end{array}$ & $\begin{array}{l}\text { Controls, } \\
\text { n (\%) }\end{array}$ & $P$-value \\
\hline \multicolumn{5}{|l|}{ Gender } \\
\hline Female & $29(73)$ & $20(72)$ & $9(75)$ & 0.822 \\
\hline \multicolumn{5}{|l|}{ Total prostheses } \\
\hline Upper and lower jaw & $10(25)$ & $9(32)$ & I (8) & \\
\hline Lower jaw only & $2(5)$ & $2(7)$ & 0 & \\
\hline Upper jaw only & $6(15)$ & $3(11)$ & $3(25)$ & \\
\hline Permanent dentures & $20(50)$ & $12(43)$ & $8(67)$ & 0.176 \\
\hline Xerostomia & $38(95)$ & $26(93)$ & $12(100)$ & 0.355 \\
\hline Periodontitis & $21(64)$ & $14(67)$ & $7(59)$ & 0.645 \\
\hline Risk for malnutrition (MNA 8-II points) & $9(39)$ & $7(39)$ & $2(40)$ & \\
\hline \multirow[t]{2}{*}{ Malnutrition (MNA <8 points) } & $12(52)$ & $9(50)$ & $3(60)$ & \\
\hline & Mean (SD) & Mean (SD) & Mean (SD) & \\
\hline Age (years) & $83(7)$ & $84(7)$ & $81(6)$ & 0.270 \\
\hline Total number of APls & $10(4)$ & II (3) & $8(4)$ & 0.092 \\
\hline Total number of teeth & $11(10)$ & $9(10)$ & $15(8)$ & 0.082 \\
\hline Oral Hygiene Index & $0.5(0.7)$ & $0.7(0.8)$ & $1.9(0.3)$ & 0.140 \\
\hline Root Caries Index & $2.1(1.6)$ & $2.3(1.6)$ & $1.7(1.6)$ & 0.391 \\
\hline MNA & $7(3)$ & $7(3)$ & $7(3)$ & 0.816 \\
\hline Hand grip, right hand (kg) & $16(7)$ & $16(7)$ & $15(7)$ & 0.744 \\
\hline Hand grip, left hand $(\mathrm{kg})$ & $15(7)$ & $15(7)$ & $14(7)$ & 0.619 \\
\hline
\end{tabular}

Notes: Statistical significance $<0.05$; $\%$ defined as valid percent of total patients in the clinic at the beginning of the data collection period. Hand grip measured by hydraulic hand grip dynamometer.

Abbreviations: APIs, active pharmaceutical ingredients; MNA, Mini Nutritional Assessment. 
(SD: 0.4) in both the groups. Regarding unstimulated salivation rates, patients with a fall history showed a mean rate of $0.3 \mathrm{~mL} / \mathrm{min}$ (SD: 0.5 ) vs $0.2 \mathrm{~mL} / \mathrm{min}$ (SD: 0.2 ) in controls $(P=0.492)$. The whole stimulated salivation rates of patients with a fall history correlated with age $(r=0.351, P=0.067)$ and xerostomia VAS ( $r=0.395, P=0.037)$. Unstimulated salivation rates correlated with subjective dysphagia $(r=0.378$, $P=0.047)$ and xerostomia VAS $(r=0.432, P=0.022)$ in this group. ORs were calculated for hyposalivation for stimulated salivation rates $(<0.7 \mathrm{~mL} / \mathrm{min})$ : $(\mathrm{OR}=1.50[95 \% \mathrm{CI}$ : $0.34,6.55], P=0.590)$; and hyposalivation for unstimulated salivation rates $(<0.2 \mathrm{~mL} / \mathrm{min})$ : $(\mathrm{OR}=1.29$ [95\% CI: 0.32 , 5.13], $P=0.722$ ). In addition, a post hoc power analysis was performed. Taking into account the results regarding the unstimulated salivation rates (defined as $<0.2 \mathrm{~mL} / \mathrm{min}$ ), power for the reported effect and sample size is $12.2 \%$. In proof of delivery of this effect with a power of at least $80 \%$, a sample size of 209 participants per group (418 cases) would be necessary in future studies.

\section{$\mathrm{XQ}$}

Regarding the XQ Part 1, only dysphagia items showed higher mean values among patients with a fall history than controls $(P=0.013)$. Detailed results are shown in Table 2. Regarding the XQ quality of life questions, almost all items

Table 2 Results of the Xerostomia Questionnaire Part I items for patients with fall history compared with controls

\begin{tabular}{|c|c|c|c|}
\hline & $\begin{array}{l}\text { Fall } \\
\text { history, } \\
\% \text { (n) }\end{array}$ & $\begin{array}{l}\text { Controls, } \\
\%(n)\end{array}$ & $P$-value \\
\hline $\begin{array}{l}\text { Oral dryness } \\
\text { No oral dryness } \\
\text { Now and then, partial } \\
\text { Always, partial } \\
\text { Completely dry, disturbing }\end{array}$ & $\begin{array}{l}18(5) \\
54(15) \\
14(4) \\
14(4)\end{array}$ & $\begin{array}{l}25(3) \\
42(5) \\
17(2) \\
17(2)\end{array}$ & 0.922 \\
\hline $\begin{array}{l}\text { Oral pain } \\
\text { No pain } \\
\text { Seldom, minimal } \\
\text { Always, strong } \\
\text { Unbearable }\end{array}$ & $\begin{array}{l}68(19) \\
32(9) \\
- \\
-\end{array}$ & $\begin{array}{l}83(10) \\
- \\
17(2) \\
-\end{array}$ & 0.961 \\
\hline $\begin{array}{l}\text { Taste loss } \\
\text { No change } \\
\text { Seldom, minimal } \\
\text { Now and then, considerable } \\
\text { Always }\end{array}$ & $\begin{array}{l}86(24) \\
4(1) \\
4(1) \\
7(2)\end{array}$ & $\begin{array}{l}92(\mathrm{II}) \\
8(\mathrm{I}) \\
- \\
-\end{array}$ & 0.202 \\
\hline $\begin{array}{l}\text { Dysphagia } \\
\text { No swallowing problems } \\
\text { Solid food } \\
\text { Soft food } \\
\text { Liquids }\end{array}$ & $\begin{array}{l}75(21) \\
14(4) \\
7(2) \\
4(1)\end{array}$ & $\begin{array}{l}100(12) \\
- \\
- \\
-\end{array}$ & $0.013 *$ \\
\hline
\end{tabular}

Note: *Statistical significance $<0.05$. showed elevated values, but no statistically significant differences were seen between groups (Table 3).

\section{Oral Health Impact Profile}

The mean OHIPG-14 total score was 10.0 (SD: 8.0) in patients with a fall history vs 7.8 (SD: 9.8) in controls, without a difference between the groups $(P=0.510)$ (Table 4$)$. In addition, none of the OHIPG-14 sub-items differed between patients with a fall history and controls, apart from less flavor in food which was reported more often by patients with a fall history $(P=0.006)$. Taste disturbances $(r=0.5$, $P=0.006)$, suffering from periodontitis $(r=0.386, P=0.084)$, and the OHI ( $r=0.306, P=0.202)$ correlated with the OHIPG-14 total scores among patients with a fall history.

\section{Discussion}

Orthogeriatric patients in our study suffered from xerostomia and hyposalivation with objective measurements for hyposalivation that were below the defined rates for whole stimulated saliva. ${ }^{23,24}$ They also reported elevated subjective xerostomia VAS values that were comparable to those from other populations, for example, patients with head and neck cancer ${ }^{37}$ which correlated with subjective dysphagia. However, no differences in subjective and objective dry mouth conditions were observed between the study groups. Therefore, contrary to our hypotheses, we could not define xerostomia and hyposalivation as independent risk factors for falling among geriatric patients. However, our study shows that orthogeriatric patients with and without fall history have impaired oral health in terms of missing remaining teeth, root caries, subjective dysphagia problems, disturbed flavor in food, and oral hygiene impairment. Furthermore, even though there were no differences between groups regarding OHrQoL, it was impaired in all participants.

Hyposalivation leads to impaired oral health, including a microbial shift that causes caries, periodontitis, loss of teeth, impaired masticatory function, and a higher risk of aspiration pneumonia among elderly patients. ${ }^{44}$ In our study, oral health was impaired among geriatric patients, albeit independently from their fall history. These indicators of impaired oral health interact with other individual and environmental risk factors, leading to faster decline, faster development of frailty, and therefore a greater risk of falls. Fewer functional teeth may lead to impaired masticatory function ${ }^{45}$ combined with oral pain, infection, root caries, and dysphagia, resulting in impaired nutritional status with weight loss, ${ }^{46} \mathrm{a}$ higher risk for orthostatic hypotension, ${ }^{47}$ and diverse hypovitaminoses such as vitamin D deficiency ${ }^{48,49}$ - all risk factors for frailty, 
Table 3 Results of the Xerostomia Questionnaire quality of life items for patients with fall history compared with controls

\begin{tabular}{|l|l|l|l|}
\hline My dry mouth... & $\begin{array}{l}\text { Fall patients, } \\
\text { mean (SD) }\end{array}$ & $\begin{array}{l}\text { Controls, } \\
\text { mean (SD) }\end{array}$ & -value \\
\hline Restricts the amount and type of food I eat & $0.4(0.8)$ & $0.6(0.9)$ & 0.617 \\
\hline Gives me an uncomfortable feeling in the mouth & $2.3(I .5)$ & $1.6(I .8)$ & 0.233 \\
\hline Makes me worry & $1.2(I .4)$ & $0.8(I .3)$ & 0.427 \\
\hline Restricts my social life & $0.2(0.5)$ & $0.8(I .2)$ & 0.140 \\
\hline Makes it awkward to eat in front of other people & $0.2(0.7)$ & $0.6(I .0)$ & 0.260 \\
\hline Makes it difficult to speak to other people & $0.5(0.9)$ & $1.1(I .6)$ & 0.262 \\
\hline Is the cause of considerable tension & $0.1(0.4)$ & $0.6(I .1)$ & 0.161 \\
\hline Makes me worry about the look of my teeth and mouth & $0.3(0.7)$ & $0.2(0.4)$ & 0.502 \\
\hline Makes me feel depressed & $0.0(0.2)$ & $0.4(0.8)$ & 0.127 \\
\hline Restricts me in my daily activities & $0.3(0.5)$ & $0.6(0.9)$ & 0.250 \\
\hline Troubles my intimate relation & $0.0(0.2)$ & $0(0)$ & 0.327 \\
\hline Gives my food less or a different taste & $0.7(1.2)$ & $0.3(0.9)$ & 0.314 \\
\hline Diminishes my will to live & $0(0)$ & $0(0)$ & $0.1(0.3)$ \\
\hline Invades every aspect of my life & $0.0(0.2)$ & $2.3(I .8)$ & 0.607 \\
\hline Cannot stay like this for the rest of my life & $2.3(1.7)$ & 0.908 \\
\hline
\end{tabular}

Note: Statistical significance $<0.05$.

and therefore associated with a higher risk for occurring falls. Dysphagia was reported more often in our fall patients compared with controls. Oropharyngeal dysphagia has been proposed as a geriatric syndrome, since it has high prevalence in older persons, is combined with other symptoms such as coughing or repetitive swallowing or aspiration, ${ }^{50}$ with high prevalence in older neurological patients, ${ }^{51}$ and shows a close interrelation with malnutrition..$^{52}$ Less flavor in food was also reported significantly more often among patients with fall history than controls. Other groups have shown that hospitalized patients were less able to taste citric acid compared to controls. ${ }^{53}$ Gustatory impairment may reduce appetite and again lead to inadequate dietary intake. Since diverse treatment options such as the use of flavor-enhanced foods or compensatory nutritional food are available, and logopedic therapy has several approaches to

Table 4 German Oral Health Impact Profile 14 items in patients with fall history compared with controls

\begin{tabular}{|c|c|c|c|}
\hline OHIPG-I 4 item & $\begin{array}{l}\text { Fall history } \\
\text { Mean (SD) }\end{array}$ & $\begin{array}{l}\text { Controls } \\
\text { Mean (SD) }\end{array}$ & $P$-value \\
\hline I. Trouble pronouncing words & $0.6(1.0)$ & $0.3(0.6)$ & 0.132 \\
\hline 2. Less flavor in food & $0.6(1.1)$ & $0(0)$ & $0.006 *$ \\
\hline 3. Life less satisfying & $1.6(1.4)$ & $1.0(1.0)$ & 0.141 \\
\hline 4. Unable to work & $0.9(1.1)$ & $0.4(1.0)$ & 0.197 \\
\hline 5. Tense feeling & $1.0(1.3)$ & $0.6(1.4)$ & 0.428 \\
\hline 6. Interrupt meals & $0.6(1.2)$ & $0.3(0.9)$ & 0.298 \\
\hline 7. Uncomfortable to eat & $0.6(1.0)$ & $0.4(1.0)$ & 0.585 \\
\hline 8. Upset & $0.6(1.1)$ & $0.8(1.4)$ & 0.679 \\
\hline 9. Trouble getting on with others & $0.9(1.1)$ & I.I (1.2) & 0.632 \\
\hline 10. Unable to function & $0.7(I . I)$ & $0.9(1.5)$ & 0.679 \\
\hline II. Being embarrassed & $0.3(0.6)$ & $0.4(0.7)$ & 0.463 \\
\hline 12. Difficulty chewing & $0.8(1.1)$ & $0.9(1.3)$ & 0.767 \\
\hline 13. Pain in oral area & $0.4(0.9)$ & $0.6(1.4)$ & 0.725 \\
\hline 14. Uncertainty & $0.4(0.8)$ & $0.3(0.6)$ & 0.578 \\
\hline Total score & $10.0(8.0)$ & $7.8(9.8)$ & 0.510 \\
\hline
\end{tabular}

Note: *Statistical significance $<0.05$.

Abbreviation: OHIPG, German version of the Oral Health Impact Profile. 
improve dysphagia problems, dentists should be aware of these problems among their patients.

Even though we were unable to show that dry mouth is an independent risk factor for the incidence of falling among this population, our data provide evidence that the complex and very individual overall combination of diverse oral health issues (with dry mouth being just one among many others) might instead be the risk factor. Accordingly, easy diagnostic tools need to be implemented in daily clinical practice for both dentists and general practitioners, since we strongly encourage both to become aware of dry mouth in their patients. Although there are currently few socially acceptable and satisfactory therapeutic approaches to increase salivation rates independent from the underlying causes, several symptomatic treatments and preventive approaches are available to reduce the consequences of hyposalivation. ${ }^{54}$

The OHrQoL in our population was impaired in patients with a fall history and in controls, but values were not outstandingly high compared to other groups. However, relatively non-symptomatic chronic dental problems might not have the same kind of impact on OHrQoL as acute pain resulting from deep carious lesions or acute infections, for example. Since subjective oral pain was reported to be very low among our population, we assume that there were no such conditions in our study population. In addition, pain perception of the elderly seems to decrease with age, ${ }^{55}$ as does self-perception and self-awareness regarding oral health not only among the elderly but also among their caregivers..$^{56}$ Furthermore, reported xerostomia, oral pain, taste loss, and dysphagia seem to represent rather minor problems in the self-perception of geriatric patients. This highlights the need for specific investigations and early intervention of these symptoms to initiate need-related intervention plans and thus potentially reduce the risk of falling.

We have investigated oral health parameters among a vulnerable population of frail geriatric patients who represent a group that is often not the focus of practicing dentists and researchers. Since maintenance of good oral health is essential in this group, our study has addressed this topic. Geriatric patients living in the community might often not be able to find their way to dentists, and ways of bringing dental medical care to this group need to be further addressed in the future. ${ }^{57}$ Furthermore, decreased self-awareness of oral symptoms has been described among other populations, that is, for swallowing dysfunction ${ }^{50}$ or dry mouth among Parkinson's disease patients. ${ }^{58}$ Our study setting, with a dentist examining in a short dental check-up, could serve as an example for regularly providing dental check-ups in a geriatric hospital setting, providing screening possibilities for older people living in the community.

The main limitation of our study is the low number of recruited controls among this vulnerable group in the predefined timespan of 5 months. This may be explained by the infrastructure of the study hospital, with a higher turnover of fall patients who were hospitalized for a shorter time than geriatric patients admitted to the hospital for other reasons. An interdisciplinary approach that includes the field of dentistry is required to better identify and define the risk factors for falling, enabling dentists, geriatricians, and general practitioners to prevent such events in geriatric patients in the community and potentially reduce the risk of falling.

\section{Conclusion}

Orthogeriatric patients with a fall history suffer from an impaired oral health, dysphagia, taste disturbances, xerostomia, and hyposalivation, and an impaired $\mathrm{OHrQoL}$, as do orthogeriatric patients without fall history. Although oral symptoms are seemingly less important in the self-perception of geriatric patients, their combined impact may increase the risk of falls and thus it is essential that dentists and geriatricians investigate, prevent, and treat these conditions.

\section{Author contributions}

All authors have contributed to the work substantially by helping with conception and study design (AGB, GR), by contributing data and recruiting patients (PS, MB, HK), and writing the manuscript (AGB, GR, MJN). All authors contributed toward data analysis, drafting and revising the paper and agree to be accountable for all aspects of the work.

\section{Disclosure}

The authors report no conflicts of interest in this work.

\section{References}

1. World Health Organization. WHO global report on falls prevention in older age; 2007. Available from: http://www.who.int/ageing/publications/Falls_prevention7March.pdf?ua=1. Accessed June 21, 2018.

2. Adams SD, Holcomb JB. Geriatric trauma. Curr Opin Crit Care. 2015;21(6): 1-526.

3. Joseph B, Phelan H, Hassan A, et al. The impact of frailty on failure-torescue in geriatric trauma patients: A prospective study. J Trauma Acute Care Surg. 2016;81(6):1150-1155.

4. Carpenter CR, Avidan MS, Wildes T, Stark S, Fowler SA, Lo AX. Predicting geriatric falls following an episode of emergency department care: a systematic review. Acad Emerg Med. 2014;21(10):1069-1082.

5. Masud T, Morris RO. Epidemiology of falls. Age Ageing. 2001; 30(Suppl 4):3-7.

6. Vellas BJ, Wayne SJ, Romero LJ, Baumgartner RN, Garry PJ. Fear of falling and restriction of mobility in elderly fallers. Age Ageing. 1997; 26(3):189-193. 
7. Tinetti ME, Williams CS. Falls, injuries due to falls, and the risk of admission to a nursing home. N Engl J Med. 1997;337(18): 1279-1284.

8. Cumming RG, Salkeld G, Thomas M, Szonyi G. Prospective study of the impact of fear of falling on activities of daily living, SF-36 scores, and nursing home admission. J Gerontol A Biol Sci Med Sci. 2000; 55(5):M299-M305.

9. Salkeld G, Cameron ID, Cumming RG, et al. Quality of life related to fear of falling and hip fracture in older women: a time trade off study. BMJ. 2000;320(7231):341-346.

10. The prevention of falls in later life. A report of the Kellogg International Work Group on the Prevention of Falls by the Elderly. Dan Med Bull. 1987;34 Suppl 4:1-24.

11. Boyé ND, Mattace-Raso FU, van der Velde N, et al. Circumstances leading to injurious falls in older men and women in the Netherlands. Injury. 2014;45(8):1224-1230.

12. Duckham RL, Procter-Gray E, Hannan MT, Leveille SG, Lipsitz LA, Li W. Sex differences in circumstances and consequences of outdoor and indoor falls in older adults in the MOBILIZE Boston cohort study. BMC Geriatr. 2013;13:133.

13. Pohl P, Nordin E, Lundquist A, Bergström U, Lundin-Olsson L. Community-dwelling older people with an injurious fall are likely to sustain new injurious falls within 5 years--a prospective long-term follow-up study. BMC Geriatr. 2014;14:120.

14. Zia A, Kamaruzzaman SB, Tan MP. Polypharmacy and falls in older people: Balancing evidence-based medicine against falls risk. Postgrad Med. 2015;127(3):330-337.

15. Huang AR, Mallet L, Rochefort CM, Eguale T, Buckeridge DL, Tamblyn R. Medication-related falls in the elderly: causative factors and preventive strategies. Drugs Aging. 2012;29(5):359-376.

16. Woolcott JC, Richardson KJ, Wiens MO, et al. Meta-analysis of the impact of 9 medication classes on falls in elderly persons. Arch Intern Med. 2009;169(21):1952-1960.

17. Tinetti ME, Han L, Lee DS, et al. Antihypertensive medications and serious fall injuries in a nationally representative sample of older adults. JAMA Intern Med. 2014;174(4):588-595.

18. Sreebny LM, Schwartz SS. A reference guide to drugs and dry mouth. Gerodontology. 1986;5(2):75-99.

19. Torres MJ, Féart C, Samieri C, et al. Poor nutritional status is associated with a higher risk of falling and fracture in elderly people living at home in France: the Three-City cohort study. Osteoporos Int. 2015; 26(8):2157-2164.

20. van Ancum JM, Pijnappels M, Jonkman NH, et al. Muscle mass and muscle strength are associated with pre- and post-hospitalization falls in older male inpatients: a longitudinal cohort study. BMC Geriatr. 2018; 18(1):116.

21. Singh M, Tonk RS. Dietary considerations for patients with dry mouth. Gen Dent. 2012;60(3):188-189.

22. Dietsch AM, A Pelletier C, Solomon NP. Saliva Production and Enjoyment of Real-Food Flavors in People with and Without Dysphagia and/or Xerostomia. Dysphagia. 2018;14:1-6.

23. Pedersen AM, Bardow A, Jensen SB, Nauntofte B. Saliva and gastrointestinal functions of taste, mastication, swallowing and digestion. Oral Dis. 2002;8(3):117-129.

24. Heintze U, Birkhed D, Björn H. Secretion rate and buffer effect of resting and stimulated whole saliva as a function of age and sex. Swed Dent J. 1983;7(6):227-238.

25. Turner MD, Hyposalivation TMD. Hyposalivation and Xerostomia: Etiology, Complications, and Medical Management. Dent Clin North Am. 2016;60(2):435-443.

26. Furness S, Worthington HV, Bryan G, Birchenough S, Mcmillan R. Interventions for the management of dry mouth: topical therapies. Cochrane Database Syst Rev. 2011;12(12):CD008934.

27. de Almeida PV, Grégio AM, Machado MA, de Lima AA, Azevedo LR. Saliva composition and functions: a comprehensive review. J Contemp Dent Pract. 2008;9(3):72-80.
28. Villa A, Wolff A, Aframian D, et al. World Workshop on Oral Medicine VI: a systematic review of medication-induced salivary gland dysfunction: prevalence, diagnosis, and treatment. Clin Oral Investig. 2015;19(7):1563-1580.

29. Atkinson JC, Wu AJ. Salivary gland dysfunction: causes, symptoms, treatment. J Am Dent Assoc. 1994;125(4):409-416.

30. Fischer D, Ship JA. The effect of dehydration on parotid salivary gland function. Spec Care Dentist. 1997;17(2):58-64.

31. Ahmad MS, Bhayat A, Zafar MS, Al-Samadani KH. The Impact of Hyposalivation on Quality of Life (QoL) and Oral Health in the Aging Population of Al Madinah Al Munawarrah. Int $J$ Environ Res Public Health. 2017;14(4):445.

32. Barbe AG, Bock N, Derman SH, Felsch M, Timmermann L, Noack MJ. Self-assessment of oral health, dental health care and oral health-related quality of life among Parkinson's disease patients. Gerodontology. 2017;34(1):135-143.

33. Komadina R, Wendt KW, Holzer G, Kocjan T. Outcome parameters in orthogeriatric co-management - a mini-review. Wien Klin Wochenschr. 2016;128(Suppl 7):492-496.

34. Cereda E. Mini nutritional assessment. Curr Opin Clin Nutr Metab Care. 2012;15(1):29-41.

35. Cruz-Jentoft AJ, Baeyens JP, Bauer JM, et al. Sarcopenia: European consensus on definition and diagnosis: Report of the European Working Group on Sarcopenia in Older People. Age Ageing. 2010;39(4): $412-423$.

36. John MT, Miglioretti DL, Leresche L, Koepsell TD, Hujoel P, Micheelis W. German short forms of the Oral Health Impact Profile. Community Dent Oral Epidemiol. 2006;34(4):277-288.

37. Dirix P, Nuyts S, vander Poorten V, Delaere P, van den Bogaert W. The influence of xerostomia after radiotherapy on quality of life: results of a questionnaire in head and neck cancer. Support Care Cancer. 2008;16(2):171-179.

38. Ainamo J, Barmes D, Beagrie G, Cutress T, Martin J, Sardo-Infirri J. Development of the World Health Organization (WHO) community periodontal index of treatment needs (CPITN). Int Dent J. 1982;32(3): 281-291.

39. Beighton D, Lynch E, Heath MR. A microbiological study of primary root-caries lesions with different treatment needs. J Dent Res. 1993;72(3):623-629.

40. Greene JC. Nutrition in a collegiate basic nursing curriculum. Nurs Outlook. 1960;8:314-315.

41. Kongstad J, Ekstrand K, Qvist V, et al. Findings from the oral health study of the Danish Health Examination Survey 2007-2008. Acta Odontol Scand. 2013;71(6):1560-1569.

42. Bardow A, Lykkeaa J, Qvist V, Ekstrand K, Twetman S, Fiehn NE. Saliva composition in three selected groups with normal stimulated salivary flow rates, but yet major differences in caries experience and dental erosion. Acta Odontol Scand. 2014;72(6):466-473.

43. Sreebny LM, Vanoczy J, Baum BJ, Edgar WM, Epstein JB, Fox PC. Saliva: its role in health and disease. Int Dent J. 1992;42(4 Suppl 2): 291-304.

44. Manabe T, Teramoto S, Tamiya N, Okochi J, Hizawa N. Risk Factors for Aspiration Pneumonia in Older Adults. PLoS One. 2015;10(10): e0140060.

45. Ikebe $\mathrm{K}$, Matsuda $\mathrm{K}$, Kagawa $\mathrm{R}$, et al. Masticatory performance in older subjects with varying degrees of tooth loss. J Dent. 2012;40(1): $71-76$.

46. Neyens J, Halfens R, Spreeuwenberg M, et al. Malnutrition is associated with an increased risk of falls and impaired activity in elderly patients in Dutch residential long-term care (LTC): a cross-sectional study. Arch Gerontol Geriatr. 2013;56(1):265-269.

47. Gangavati A, Hajjar I, Quach L, et al. Hypertension, orthostatic hypotension, and the risk of falls in a community-dwelling elderly population: the maintenance of balance, independent living, intellect, and zest in the elderly of Boston study. J Am Geriatr Soc. 2011;59(3): 383-389. 
48. Bischoff-Ferrari HA, Dawson-Hughes B, Staehelin HB, et al. Fall prevention with supplemental and active forms of vitamin D: a metaanalysis of randomised controlled trials. BMJ. 2009;339:b3692.

49. Latham NK, Anderson CS, Reid IR. Effects of vitamin D supplementation on strength, physical performance, and falls in older persons: a systematic review. J Am Geriatr Soc. 2003;51(9):1219-1226.

50. Baijens LW, Clavé P, Cras P, et al. European Society for Swallowing Disorders - European Union Geriatric Medicine Society white paper: oropharyngeal dysphagia as a geriatric syndrome. Clin Interv Aging. 2016;11:1403-1428.

51. Kikawada M, Iwamoto T, Takasaki M. Aspiration and infection in the elderly: epidemiology, diagnosis and management. Drugs Aging. 2005;22(2):115-130.

52. Carrión S, Cabré M, Monteis R, et al. Oropharyngeal dysphagia is a prevalent risk factor for malnutrition in a cohort of older patients admitted with an acute disease to a general hospital. Clin Nutr. 2015; 34(3):436-442.

53. Toffanello ED, Inelmen EM, Imoscopi A, et al. Taste loss in hospitalized multimorbid elderly subjects. Clin Interv Aging. 2013;8:167-174.
54. Barbe AG, Schmidt-Park Y, Hamacher S, Derman SHM, Noack MJ. Efficacy of GUM ${ }^{\circledR}$ Hydral versus Biotène ${ }^{\circledR}$ Oralbalance mouthwashes plus gels on symptoms of medication-induced xerostomia: a randomized, double-blind, crossover study. Clin Oral Investig. 2018;22(1): 169-180.

55. Lautenbacher S, Peters JH, Heesen M, Scheel J, Kunz M. Age changes in pain perception: A systematic-review and meta-analysis of age effects on pain and tolerance thresholds. Neurosci Biobehav Rev. 2017;75:104-113.

56. Reis SC, Marcelo VC, da Silva ET, Leles CR. Oral health of institutionalised elderly: a qualitative study of health caregivers' perceptions in Brazil. Gerodontology. 2011;28(1):69-75.

57. de Baat C, de Baat P, Gerritsen AE, Flohil KA, van der Putten GJ van der Maarel-Wierink CD. Risks, consequences, and prevention of falls of older people in oral healthcare centers. Spec Care Dentist. 2017;37(2):71-77.

58. Barbe AG, Heinzler A, Derman S, Hellmich M, Timmermann L, Noack MJ. Hyposalivation and xerostomia among Parkinson's disease patients and its impact on quality of life. Oral Dis. 2017;23(4):464-470.
Clinical Interventions in Aging

\section{Publish your work in this journal}

Clinical Interventions in Aging is an international, peer-reviewed journal focusing on evidence-based reports on the value or lack thereof of treatments intended to prevent or delay the onset of maladaptive correlates of aging in human beings. This journal is indexed on PubMed Central, MedLine,

\section{Dovepress}

CAS, Scopus and the Elsevier Bibliographic databases. The manuscript management system is completely online and includes a very quick and fair peer-review system, which is all easy to use. Visit http://www.dovepress. com/testimonials.php to read real quotes from published authors. 